\title{
In Memoriam Elena Górriz Royo
}

\author{
JosÉ L. GonZÁLEZ CuSSAC \\ Catedrático Derecho Penal \\ Universidad de Valencia
}

\begin{abstract}
En la madrugada del pasado 1 de noviembre moría ELENA GÓRRIZ ROYO. Tenía 46 años. Todavía no lo creo. No puedo ni quiero. Es contra natura escribir una nota necrológica de una discípula tan joven. Tan querida y admirada desde que fue una inquieta estudiante en la Universitat Jaume I en los primeros años noventa. Pero para mantener vivo su recuerdo es necesario sobreponerse al inmenso dolor de su pérdida.
\end{abstract}

Impartió su última clase en la mañana del 10 de octubre: "Derecho Penal I (Parte General)", siempre en lengua inglesa, a su querido Grupo ARA (Alto Rendimiento Académico). Su última conferencia la dictó, también en el Departamento de Derecho Penal de la Facultad de Derecho de la Universidad de Valencia, en la tarde del 3 de octubre. Llevó por título "Compliance programs en delitos medioambientales", dentro de las IV Jornadas "Las respuestas penales a los retos del buen gobierno". Esa misma mañana las había presentado en calidad de co-directora, junto a las autoridades académicas y de la Generalitat Valenciana presentes.

La cercanía de estas dos fechas con la de su prematuro y cruel fallecimiento nos ofrecen un rasgo esencial de su personalidad. Hasta el final estuvo cumpliendo sus obligaciones académicas. Y lo hizo con alegría, con rigor, con pasión. Sin una mueca de dolor ni queja alguna. Como si la enfermedad no fuera con ella.

Fue una académica por convicción y dedicación. Infatigable trabajadora, de una curiosidad intelectual insaciable, persistente en la defensa de sus tesis, de profundas convicciones progresistas, comprometida con la lucha por la 
igualdad de las mujeres, y de una generosidad ilimitada que la hacía estar siempre dispuesta a colaborar, a ayudar, a compartir y sobre todo a emprender nuevos proyectos.

Se Licenció en Derecho (1991-1995) y Doctoró en Derecho (2001) con Premio Extraordinario. Fue Becaria FPI de la Generalitat Valencia; disfrutó de una beca post-doctoral y fue profesora ayudante (2004). Todo ello en la Universitat Jaume I de Castellón. Fue Asesora jurídico-penal en el Gabinete del Ministerio del Interior en Madrid (2004-2005). Puesto en el que dimitió al haber ganado una de las tres plazas de Profesor Titular en el concurso-oposición celebrado en la Universidad de A Coruña, en el marco del sistema de habilitaciones (2005). De este modo accedió a una plaza de Profesora Titular de derecho penal en la Universidad de Valencia. Destino que ha ocupado hasta su prematura muerte.

Publicó cinco monografías como autora única, y más de cuarenta trabajos científicos en revistas y en capítulos de libro. Dirigió tesis doctorales, congresos, seminarios y proyectos públicos financiados. Realizó múltiples estancias de investigación en Universidades extranjeras: Universität Johannes Kepler de Linz (Austria); Facoltá di Giurisprudenza della Universitá degli Studi Roma Tre (Italia); Institut für Krilminollogie und Wirtschaftsstrafrehct de la Universidad de Freiburg i. Br. (Alemania); Center for the Administration of Justice de la Florida International University (Miami, EEUU); Max Planck Institut Für Auslandiches und International Strafrecht, en Freiburg i. Br. (Alemania); y, Institute for Legal Research, School of Law, de la UC Berkeley (California, EEUU). La enfermedad le impidió disfrutar de una estancia en la School of Law de la Harvard University, en 2018, en la que había sido aceptada como investigadora.

Impartió la docencia en grado, post-grado y doctorado, transmitiendo su pasión por el estudio riguroso del Derecho penal. Y siempre obtuvo la recompensa en el afecto y reconocimiento de sus alumnos. 
En poco más de veinte años de vida profesional este es un apresurado resumen de su intensa actividad: incansable.

Pero si hay una línea de investigación permanente en la trayectoria de ELENA GÓRRIZ ROYO es la relativa a los delitos contra el medio ambiente y la ordenación del territorio. A ella consagró gran parte de su obra científica, de sus conferencias, clases, seminarios y proyectos. Otra muestra destacada de su interés y dedicación a esta materia la constituye precisamente su colaboración en la Revista que amablemente acoge estas líneas.

Además de varios artículos y capítulos de libros, destacaré sus dos monografías. La primera, "Protección penal de la ordenación del territorio" (Tirant lo Blanc, 2003), contenía en esencia su Tesis Doctoral. Fue pionera en su tratamiento y desde entonces una referencia de primer orden. Poco después publicó "Los delitos de prevaricación urbanística" (Tirant lo Blanch, 2004). Con la misma completó el abordaje de estas nuevas figuras introducidas en el Código Penal de 1995.

Su pasión por la temática medioambiental fue constante. Así, su ultimo trabajo publicado días antes de su muerte ha sido "Compliance penal ambiental" (InDret, octubre 2019). Y en junio de este mismo año le fue notificada la concesión de un Proyecto I+D del Ministerio, que en calidad de Investigadora Principal junto a la Dra. Matallín Evangelio, tenía que desarrollar en los próximos tres años. Se titula "Criminal Compliance Programs y elaboración de mapas de riesgo. En especial en delitos ambientales y de corrupción".

Se ha truncado una brillante y comprometida trayectoria académica, a la que esperaba un porvenir fructífero. Pero por muchos años sus trabajos seguirán siendo de obligada consulta, en especial, los relativos al Derecho penal del medio ambiente y a su estrecha vinculación con los delitos de corrupción, que tan acertadamente conectó. Su rigor, creatividad y oportunidad serán ejemplo para todos nosotros. 
En lo personal su pérdida es irreparable. Provoca un dolor insoportable. Un vacío constante. Proyectos truncados. Vidas rotas. Todo incrementado por su juventud. Por su hermosa personalidad. No nos queda más que el consuelo de haber tenido la fortuna de conocerla, de compartir muchos años con la compañera generosa, con la colega inteligente y sobre todo con la fiel amiga. También nos queda el deber de honrar su memoria. De expresar todo nuestro reconocimiento y cariño. Con nosotros, junto a su querida familia, permanecerá siempre tu entrañable recuerdo. Querida Elena, no te olvidaremos nunca.

Valencia, 1 de diciembre de 2019 